\title{
Foreign Direct Investment as a Factor of Iron and Steel Industry Development in Russia
}

\author{
Oleg Bazhenov ${ }^{1, *}$ Angelina Ilyina ${ }^{1}$ Anna Oykher ${ }^{2}$
}

\author{
${ }^{1}$ Department of Accounting, Analysis and Audit, Ural Federal University, Ekaterinburg, Russia \\ ${ }^{2}$ Department of Machinery Production Organization, Ural Federal University, Ekaterinburg, Russia \\ *Corresponding author. E-mail o.v.bazhenov@urfu.ru
}

\begin{abstract}
The research paper defines and describes the factors and the impact of foreign direct investment (FDI) on iron and steel industry enterprises. For this purpose the following objectives have been gradually achieved: 1) Identifying FDI factors, which affect economic performance of iron and steel industry enterprises; 2) Building an econometric regression model for basic iron and steel industry enterprises in Russia on the basis of publicly available information; 3) Interpreting statistical modeling results. The research was carried out using the comparative analysis methods and the methods of summarizing the information gathered from various sources. The authors have conducted a content analysis of recent analytical Russian and foreign keynote publications. In addition, we have completed the analysis of strategic data (panel data), based on which a regression model has been designed. The model has been estimated by Ordinary Least Squares (OLS), where the revenues of iron and steel industry enterprises appeared as a dependent variable and the size of FDI, capital and supplies of enterprises appeared as an explanatory (independent) variable. The following conclusion has been drawn from the present study: foreign direct investment is one of the key components of both the national economic development and the development of iron and steel industry. Foreign direct investment has the most significant positive impact on large metallurgical enterprises, which hold a considerable share of foreign investment. Theses and conclusions presented in the study can be applied by the managers of metallurgical holdings as a theoretical basis for corporate development programs, and by regional authorities and executive powers for identifying the directions of improving investment appeal of the region.
\end{abstract}

Keywords: iron and steel industry, foreign direct investment, regression analysis, comparative analysis,

Ordinary Least Squares

\section{INTRODUCTION}

Currently Russian economy is undergoing a substantial decrease, caused to the great extent by the influence of the geopolitical factors.

In these circumstances, we observe foreign investment outflow from the country and a decrease of foreign direct investment (FDI). FDI is one of the most important components of international economic transactions and it has a major impact on both entire economy and a particular industry (for instance, iron and steel industry, which has been studied in this paper and which is known as one of the most advanced industries, holding a welldeveloped infrastructure and technology base) [1]. Meanwhile, foreign direct investment has not always a positive impact on enterprise's performance and that has been illustrated in a number of studies $[2,3,4,5,6]$.

The primary aim of this study is to determine the factors and to what extent FDI influences on iron and steel enterprises and also the causes of their negative or positive impact.

The objectives of the study are:
1) To identify FDI factors, which affect economic performance of iron and steel industry enterprises;

2) To build an econometric regression model for basic iron and steel industry enterprises in Russia on the basis of publicly available information;

3) To interpret statistical modeling results.

Subject matter of the study is foreign direct investment.

Scope of this study is the impact of foreign direct investment (FDI) on iron and steel industry enterprises in Russia.

Theoretical basis of the study: scientific works of Russian and foreign authors, devoted to the examination of the impact of foreign direct investment (FDI) on industries of developing economies: S.M. Kadochnikov, J. Konings, S.L. Brainard, S. Diankov and B. Hoekman, B. K. Smarzynska, K. Zukovska-Gagelmann, etc.

Thus, we have formed the content of the paper following the logic of the objectives, which have been formulated above. For this purpose, at an early stage we will examine and describe a term 'foreign direct investment'.

Traditionally, in Russia foreign direct investment is when an individual or business acquires 10 percent or more of 
the shares of a foreign company's authorized capital stock [7].

In modern economics FDI is being studied in the context of various theories. All of them have been developed as part of patterns of international trade, where FDI is regarded to a cross-country capital migration $[8,9]$.

\section{THE RESEARCH METHOD}

Different theories of international trade can be the theoretical framework for analysis of welfare efficiency from FDI. However, for the purposes of the research we will take a detailed look only several patterns at related to the theories mentioned above.

The gravity model of international trade (by Brainard, S. L.) [10]. The basic model for trade between two countries ( $i$ and $j$ ) takes the form of

$$
F_{i j}=\frac{M_{i} M_{j}}{D_{i j}}
$$

Where $F_{i j}$ is the FDI flow from a country $j$ to a country $i$; $\mathrm{M}_{\mathrm{i}}$ и $\mathrm{M}_{\mathrm{j}}$ are the economic masses of each country (GDP); $\mathrm{D}_{\mathrm{ij}}$ is the distance between the countries [2].

One of the studies devoted to the analysis of intra-industry externalities is the work of J. Konings [4], which can be used for estimation of externalities on the industries in developing economies. The author of the model estimates a log-linear production model through using Ordinary Least Squares, supplemented with Generalized Method of Moments (GMM) with instrumental variables for panel data.

A regression model has the following form:

$\Delta \ln Y_{i t}=\beta_{0}+\beta_{1} \Delta \ln L_{i t}+\beta_{2} \Delta \ln L_{i t}+\beta_{3} \Delta \ln L_{i t}+$ $+\beta_{4} \Delta \ln L_{i t}+\beta_{5} \Delta \ln L_{i t}+\beta_{6} \Delta \ln L_{i t} * * \Delta F D l_{j t}+\varepsilon_{i t}$ Where $\Delta \ln Y_{i t}$ is a dependent variable indicating the increase in $\ln$ of firm i's output in the period $t$, and independent variables :

$\Delta \ln L_{i t}$ - increase in ln of the number of employed in the company over the period;

$\Delta \ln K_{i t}$ - increase in ln of amount of capital over the period; $\Delta \ln M_{i t}$ - increase in $\ln$ of stock volume, used in the company over the period;

$F D I_{i}$ - an $F D I$ share on a particular enterprise, reflecting direct impact of presence of foreign investment on the enterprise on its output;

$\triangle F D I_{j t}$ - a variable enabling to estimate externalities of $F D I$ in the industry;

Table 1 Concentration indicators in the economy, 2013-2015
$F D I_{i} * \Delta F D I_{j t}$ - a variable indicating the impact of presence of foreign investors in the industry on the output of FDI enterprises;

$\beta_{0}-$ intercept term;

$\beta_{1}$ - weighting factor of a variable $\Delta \ln L_{i t}$;

$\beta_{2}$ - weighting factor of a variable $\Delta \ln K_{i t}$;

$\beta_{3}$ - weighting factor of a variable $\Delta \ln M_{i t}$

$\beta_{4}$ - weighting factor of a variable $F D I_{i}$;

$\beta_{5}$ - weighting factor of a variable $\triangle F D I_{j t}$;

$\beta_{6}$ - weighting factor of a variable $F D I_{i}{ }^{*} \Delta F D I_{i t}$;

$\Delta \varepsilon_{i t}$-increment of a regression equation's reminder.

Thus, in the authors' opinion, a model by Konings can be applied in the analysis of Russian iron and steel industry (in particular - the impact of foreign direct investment). Furthermore, it is worth examining a market structure using macroeconomic tools in order to determine a possibility of presence of negative market impacts.

Iron and steel industry is known as one of the most advanced industries in Russia due to its well-developed infrastructure and technology base. Russia is the fourthlargest steel producer (as at 2015) - after China, Japan and India [11].

Iron and steel industry is one of the first sectors of Russian industrial complex, which has launched Programme for production restructuring and capacity reductions in unviable lines; these measures in their turn significantly improved its competitiveness and enabled to reduce costs.

Besides, the characteristics of Iron and steel market are determined by specification of the product itself. This is the industry which integrates ore extraction beneficiation plants (as well as non-metallic materials), plants for the production of refractories, coke chemical industry products, cast iron, rolled steel, ferroalloys, steel and castiron pipes and downstream products (e.g. rail fastenings). The industry also provides the basis for machine-building and construction.

For iron and steel market analysis the authors have reviewed 19 largest enterprises of this industry in Russia.

First, we have estimated market capacity. It has been determined as total revenue of all enterprises located in Russia.

In 2013 the amount was 1533333637 thousand rubles, in 2014 - 146646565 thousand rubles and in 2015 1625917312 thousand rubles $[12,13]$.

For measuring concentration level we used the following indicators [14]: concentration ratios, HerfindahlHirschman index, Tideman-Hall index, Entropy Concentration index, Logarithmic dispersion of market shares and Gini coefficient.

Data obtained are presented in Table 1.

\begin{tabular}{|c|c|c|c|}
\hline \multirow{2}{*}{ Indicator } & \multicolumn{3}{|c|}{ Value } \\
\hline & 2013 & 2014 & 2015 \\
\hline Number of firms & \multicolumn{3}{|c|}{19} \\
\hline Concentration ratio CR2 & 0,315 & 0,307 & 0,325 \\
\hline Concentration ratio CR3 & 0,461 & 0,452 & 0,469 \\
\hline Concentration ratio CR4 & 0,546 & 0,539 & 0,555 \\
\hline Herfindahl-Hirschman index HHI & 0,098 & 0,097 & 0,101 \\
\hline Tideman-Hall index THI & 0,102 & 0,102 & 0,105 \\
\hline Entropy Concentration index ECI & 2,544 & 2,549 & 2,520 \\
\hline Logarithmic dispersion of market shares D & 2,487 & 2,560 & 3,344 \\
\hline Gini coefficient $\mathrm{G}$ & 0,514 & 0,511 & 0,516 \\
\hline
\end{tabular}


Thus, according to the results obtained (namely, estimation of concentration indicators: CR2, CR3, CR4), we can see just minor changes in dynamics: compared to 2013 in 2014 the concentration decreases, and in 2015 - it increases; in each case the concentration rate is average. Herfindahl-Hirschman index value leads to the conclusion that in 2013 and 2014 a market concentration ratio was low, while in 2015 - it was medium.

Tideman-Hall index value demonstrates a medium market concentration ratio and the absence of significant changes in the dynamics.

Entropy Concentration index supports the conclusion of a medium market concentration ratio, in the dynamics the values vary only slightly, the absence of redistribution on the market.

Compared with 2013, the change in Logarithmic dispersion of market shares in 2014 was non-significant, however, in 2015 this indicator has increased, what can be interpreted as a modest increase of market concentration. Values of Gini coefficient lead to the conclusion of the moderate distribution of market shares of iron and steel industry enterprises.

Thus, the market structure can be defined as similar to oligopoly with 3 leaders: PJSC "Magnitogorsk Iron and Steel Works", OJSC "Novolipetsk Steel" and PJSC "Severstal".

The current economic situation has not had a great impact on the financial situation of the majority of iron and steel industry enterprises; furthermore, their economic situation had improved in 2015. This was due to the devaluation of the national currency, when a considerable share of sales accounts for export and costing is carried out in rubles. Also profitable growth was made possible by falling prices of ore and coal. In 2015 Russian metallurgical enterprises have opted for cost optimization.

While in 2014 they successfully cut expenses, by 2015 they have managed to achieve the target of disposal of non-core and non-performing assets [1].

Assessing the foreign direct investment dynamics we can note the following. According to data of Federal State statistics service and the report of the United Nations conference [15], two positive trends of FDI size can be found: from 2002 to 2007 and from 2010 to 2013. From 2007 to 2016 a negative trend of FDI size can be seen, which is associated with the global financial crisis. Furthermore, the size of FDI decreased by $27 \%$ in 2015.

Policy-making, targeted at attraction of foreign direct investment, usually entails the modernization of enterprise's production structure in developing countries, upgrading of infrastructure and staff training. Accordingly, industrial policy mostly focuses on enterprises restructuring through attracting FDI. Despite the significant positive effect of FDI, some negative effects also might become apparent in Russian companies, among them the migration of skilled workers in affiliates of TNCs as well as increasing competition from TNCs, which can reduce the market share of local enterprises. In most cases the inflows of foreign direct investment occur through the establishment of TNCs' brunches.

Next, we have undertaken an econometrical study of foreign direct investment, targeted at the development of iron and steel enterprises.

For the purposes of the study we have chosen 19 metallurgical companies (the mentioned above). A model by J. Konings was used as the basis. After simplification the model was written as:

$$
Y_{i t}=\beta_{0}+\beta_{1} F D l_{i t}+\beta_{2} K_{i t}+\beta_{3} M_{i t}+\varepsilon
$$

where $Y_{i t}$ - dependent variable indicating total revenue of $i$-company in the period $\mathrm{t}$, and independent variables :

$F D I_{i t}-F D I$ share, reflecting direct impacts;

$K_{i t}$ - amount of capital over the period;

$M_{i t}$ - stock volume, used in the company over the period; $\beta_{0}$ - intercept term;

$\beta_{1}$-weighting factor of a variable $F D I_{i t}$

$\beta_{2}$ - weighting factor of a variable $K_{i t}$

$\beta_{3}$ - weighting factor of a variable $M_{i t}$

$\varepsilon-$ regression equation's reminder.

Thus, the study was based on panel data of 19 companies for 8 years (2008-2015) and the total dimension of the sample was 120 observations (the maximum number is 152 , but due to the absence of some of the data for some of the periods, the sample was reduced by 32 observations) $[12,13]$.

Analysis of values of variables correlation coefficient has shown that there is a correlation between independent variables, and this enables us to conclude that there may be a problem of multicollinearity in the model. Furthermore, coefficients demonstrate a relationship between dependent and independent variables, and because of that variables may be considerable in estimating.

Thus, we have built a linear regression model, estimated using Ordinary Least Squares (OLS) with the aid of the software package EViews 9.5.

Table 2 The results of estimation of linear regression model using ols methodndica

\begin{tabular}{|l|c|c|c|}
\hline \multicolumn{1}{|c|}{ Variable } & C & FDI & K \\
\hline Coefficient & 13216873,00 & $-0,38$ & 0,15 \\
\hline Significance level & $1 \%$ & $10 \%$ & 9,48 \\
\hline
\end{tabular}

Then the estimated model can be written as:

$$
\hat{Y}_{i t}=13216873-0,38 F D l_{i t}+0,15 K_{i t}+9,48 M_{i t}
$$

Thus, interpretation of the estimated model can be the following: the coefficient of determination (R2) is 0,883 , what means that explanatory power of the model equals $88,3 \%$; with an increase in FDI size by 1000 rubles the total revenue will decrease by 380 rubles; with an increase in the amount of capital by 1000 rubles the total revenue will increase by 150 rubles and with an increase in the amount of materials by 1000 rubles the total revenue will increase by 9480 rubles.

The fact that with an increase in FDI size total revenue decreases, can be attributed to the presence of negative intra-industry effects from FDI, caused by insufficient 
[3] S. Diankov, B. Hoekman "Foreign investment and productivity growth in Czech enterprises", The World Bank Economic Review, 2000, Vol. 14 (1), p. 49-64.

[4] J. Konings "The effect of foreign direct investment on domestic firms: Evidence from firm-level panel data in emerging economies", Economics of Transition. 2001, Vol. 9 (3), p. 619-633.

[5] B.K. Smarzynska "Determinants of spillovers from foreign direct investment through backward linkages", The World Bank, July 2002. Mimeo.

Thus, in this paper the authors have reviewed and examined the results and findings of empirical studies and models offered by Russian and foreign authors, which determine the nature of FDI.

Analysis of the Russian iron and steel industry has shown that there are three largest companies present in the market, and that their shares grow in dynamics, in spite of conjunctural changes in the national economy. This research allows to confirm the presence of negative externalities in the industry.

Furthermore, based on panel data of 19 companies for 8 years, we have built an econometric model by the following indicators: total revenue, amount of capital, amount of capital, amount of materials and size of FDI; the model has been estimated using Ordinary Least Squares. The results obtained have also confirmed the presence of negative externalities in the industry, since the coefficient of the variable, indicating foreign direct investment is a minus coefficient.

Thus, in the current difficult economic situation foreign direct investment become an important element of economic development of the country and the industry under consideration. Meanwhile, foreign direct investment has a positive impact on large metallurgical enterprises, that have major participation of foreign capital, which enables them to compete more effectively in global markets.

\section{REFERENCES}

[1] Trends in the development of Russian ferrous metallurgy market. Overview of iron and steel market, Deloitte, page 16. accessed on October 2, 2019 <https://www2.deloitte.com/content/dam/Deloitte/ru/D ocuments/manufacturing/russian/ru-iron-and-steelindustry-report-ru.pdf>

[2] S.M. Kadochnikov "Foreign direct investment in transition economies”, Ekonomika regiona, 2005, №4. pp. $140-170$
[6] K. Zukovska-Gagelmann "Productivity spillovers from foreign direct investment in Poland", Economic Systems, 2000, Vol. 24 (3), p. 223-256

[7] S.M. Kadochnikov. Foreign direct investment: a microeconomic analysis of the welfare effects.

Textbook, SPb.: Jekonomicheskaja shkola, 2002, P. 267.

[8] I.M. Drapkin., O.S. Mariej \& K.V.Chukavina "Quantitative assessment of the potential import and export of foreign direct investment in the Russian economy on the basis of the gravity approach", Zhurnal Novoj jekonomicheskoj associacii, 2015, Vol. 4 (28), p. 75-95.

[9] I.A. Filippova The global economy and international business: a tutorial, Ulyanovsk: ULSTU, 2008, 168 p.

[10] S.L. Brainard "An Empirical Assessment of the Proximity Concentration Tradeoff between Multinational Sales and Trade", American Economic Review, 1997, Vol. 87 (4), p. 520-544.

[11] Worldsteel association, accessed on October 2, 2019 <https://www.worldsteel.org/statistics>

[12] Prime Disclosure, accessed on October 2, 2019 <https://disclosure.1prime.ru>

[13] Disclosure Server - Interfax, accessed on October 2, 2019 <https://www.e-disclosure.ru>

[14] S.B. Avdasheva, N.M Rozanova. The theory of industrial organization, M.: Izd-vo Magistr, 1998, 320 p.

[15] The Federal State Statistics Service, accessed on October 2, $2019<\mathrm{http}: / /$ www.gks.ru> 